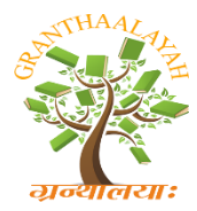

Science

\title{
SONOGRAPHIC EVALUATION OF OUTFLOW VEINS IN SUDANESE LIVER TRANSPLANTS
}

\author{
Ashraf Mustafa Mohammed Osman ${ }^{1}$, Professor. Dr. Mohammed Al Fadil Gar al naby ${ }^{2}$, \\ Dr. Asma Ibrahim Ahmed ${ }^{3}$, Dr. Babiker Abd Elwahab Awad alla 4 \\ ${ }^{1}$ Sahiroon Specialized Hospital [MBBSc, MSc] \\ ${ }^{2}$ Professor of Radiology in Sudan University [MSc, $\left.\mathrm{PhD}\right]$ \\ ${ }^{3}$ Associate Professor of Radiological Sciences, College of Medical Radiological Sciences, \\ Sudan University of Science and Technology [MSc, PhD] \\ ${ }^{4}$ Lecturer in College of Medical Radiological Sciences, Sudan University of Science and \\ Technology [B.Sc., COMRS, PhD]
}

\begin{abstract}
The purpose of this study was to identify the specific Doppler criteria for the outflow vein (hepatic veins and inferior vena cava) obstruction in liver transplants. A case control study was done after performing venous Doppler sonographic studies in 300 normal (control) and 45 liver transplant cases (4 whole liver, 41 lobar) with no vascular obstruction. The ultrasonic Doppler study were classified as normal, occluded, or stenosed on the basis of gray scale and color flow mapping appearances as well as elevated or absent waves. The following Doppler parameters were evaluated: the outflow veins on color Doppler interrogation, venous pulsatility index on spectral trace. Receiver operating characteristic curves were constructed. There were no cases of outflow vein obstruction found in our sample (neither stenosis, nor occlusion). Mean venous pulsatility index for normal outflow veins was 0.75 and is found ranging between $(0.55-0.75)$. A venous pulsatility index of $<0.45$ is specific for stenosis (5). The venous pulsatility index is a useful parameter for diagnosing venous stenosis in liver transplants.
\end{abstract}

Keywords: Doppler Ultrasonography; Hepatic Veins; IVC; Liver Transplants.

Cite This Article: Ashraf Mustafa Mohammed Osman, Dr. Mohammed Al Fadil Gar al naby, Dr. Asma Ibrahim Ahmed, and Dr. Babiker Abd Elwahab Awad alla. (2018). "SONOGRAPHIC EVALUATION OF OUTFLOW VEINS IN SUDANESE LIVER TRANSPLANTS." International Journal of Research - Granthaalayah, 6(12), 77-83. https://doi.org/10.5281/zenodo.2528461.

\section{Introduction}

Doppler ultrasound plays an important role in the postoperative management of hepatic transplantation, by enabling early detection and treatment of various vascular complications. This paper describes the normal Doppler findings in the outflow veins following liver transplantation 
and reviews the imaging appearances of various vascular complications associated with it. It also discusses transient waveform abnormalities, often seen on a post-transplant Doppler examination, and the importance of differentiating them from findings suggestive of ominous vascular complications of the hepatic veins and IVC.

Thrombosis and stenosis are two rare complications of the IVC and hepatic veins, after hepatic transplantation. The venous complications tend to occur at the anastomosis and knowledge of the surgical anatomy is useful. The incidence of hepatic venous outflow stenosis is higher in living donors and split graft liver pediatric grafts than in whole liver grafts, likely due to the size mismatch and small anastomosis. [Wang SL, et al. 2005]. Most hepatic venous stenosis present late, many months to years after transplantation. [Buell JF, et al. 2002].

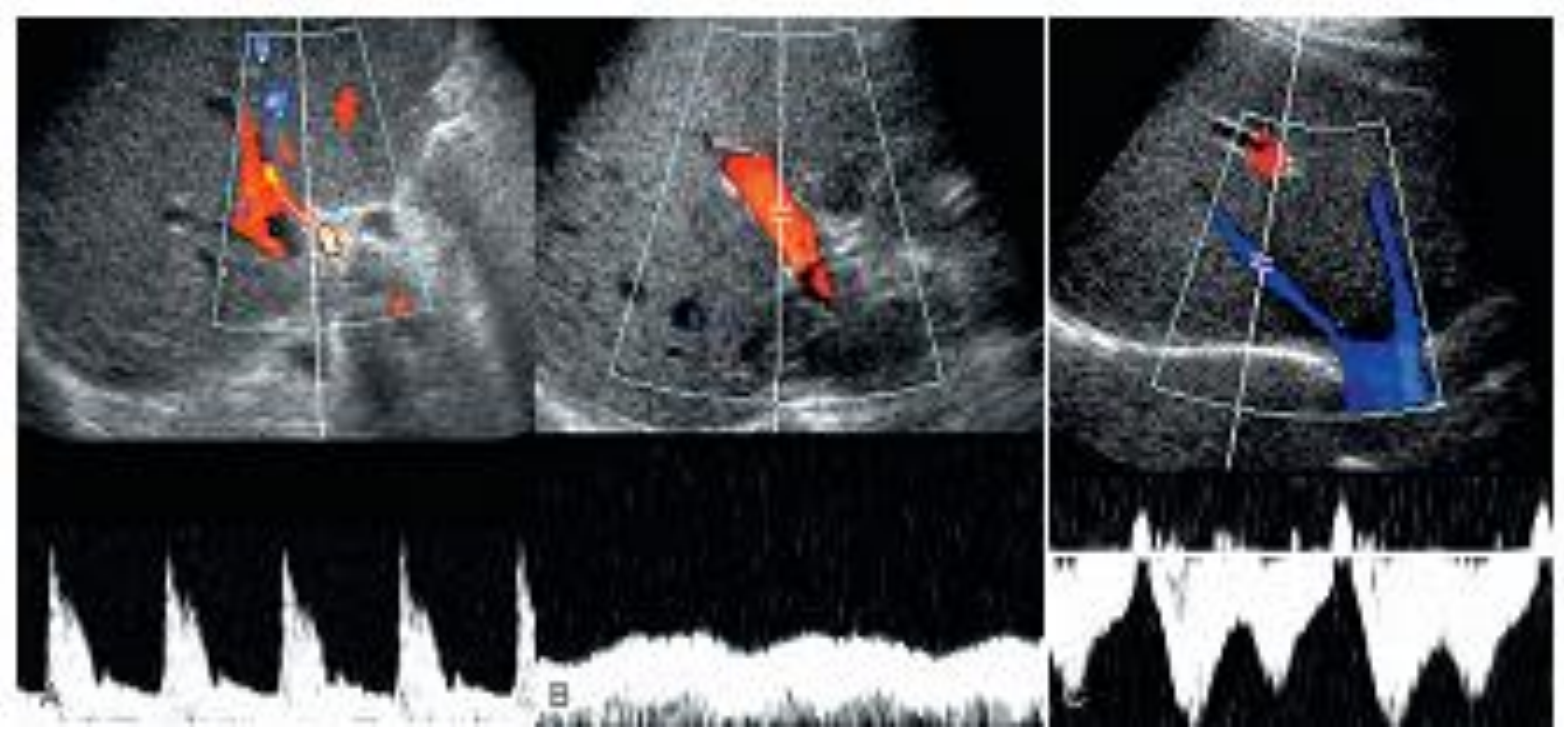

Figure 1: Normal liver transplant: color and spectral Doppler. Color and spectral Doppler images of normal A, hepatic artery; B, main portal vein; and C, right hepatic vein. (From Crossin J, Muradali D, Wilson SR. Ultrasound of liver transplants: normal and abnormal. Radiographics 2003; 23:1093-1114.)

Normal hepatic veins have a triphasic waveform due to transmission of cardiac pulsations from the heart. Hepatic venous stenosis prevents transmission of the cardiac pulsations, resulting in loss of triphasicity. [ Tamsel S, et al 2007., and Ko EY, et al. 2003] However, loss of triphasicity is a very nonspecific finding and is often seen in normal postoperative patients. Therefore, while the presence of hepatic venous triphasicity can be used to exclude hepatic venous stenosis, loss of triphasicity does not imply the presence of a hepatic venous complication. Clinically significant hepatic venous outflow stenosis can be treated with venous angioplasty and stenosis. [ Buell JF, et al. 2002].

\section{Materials and Methods}

Material: Equipment: Data collection sheets. Couch; pillow; bed sheet; cover; sterile gloves; acoustic gel. Two ultrasound machines of complete capabilities (ALOKA prosound; SSD-3500SX, 
and TOSHIBA US SYSTEM); with two probes (curvilinear $=3.5-7 \mathrm{MHz}$ and linear $=7.5-12$ $\mathrm{MHz})$.

Method: The study done during the period from $1^{\text {st }}$ April 2016 to $30^{\text {th }}$ July 2017.The design used in this study, was the analytical case control study; the case here is the transplanted liver vessels outflow direction, waveforms, and velocity (45, 4 whole liver , 41 lobar) and the control was the expected normal students hepatic venous liver flow direction and velocity (300). The data collected from 300 normal objects population; students of faculty of medicine in Al Rabat University (aged between 16-22 yrs., $48 \%$ Male; 52\% Female); and 45 out of only 65 patients in Sudan with transplanted liver, 9 of them was children (aged between 1.5 - 65 years. ), $76 \%$ Males; $24 \%$ Females, has been tested and enter the study.

Inclusion Criteria in the Case: Sudanese people that underwent liver transplantation, male or a female, adult or a child.

Exclusion Criteria in the Case: very ill or rejected liver transplantation (social and familial purposes).

Sample Size and Type: The data of this study collected from the 345 objects, 300 of them was young normal volunteers selected randomly. The other 45 objects were those with liver transplantation.

Methods of Data Collection and Technique: Using the data sheet to collect the data, we perform both transverse and longitudinal ultrasound techniques plus coronal oblique; putting the transducer in four main points:

1- the mid-line, 2- the mid clavicular line,3- the anterior and 4- the mid axillary lines all are intercostally line that made a perpendicular imaginary line from the xiphisternum. In addition, sub costal scan is done in the same points.

Variables of Data Collection: The data of this study collected using the following variables: the liver texture in both case and control objects as well as the hepatic veins pulsatility index in both normal livers and transplanted one. This end with the hepatic veins and the inferior vena caval spectral trace to know the waveform character.

Methods of Data Analysis: Using the suitable above-mentioned techniques, these all variables collected to create the data. Finally these data is tabulated, described, represented and analyzed using SPSS version 20, putting in mind that the p value is 0.01 using the chi square test as well as the t-tailed test [ $\mathrm{p}$ value is $0.05, \mathrm{R} 2<1$,when it is near to one it is significant for good relation] to know the significance. The results of this analysis put in a scientific frames and facts from which the medical decision and recommendations is created.

Ethical Approval: Ethical approval has been granted from the hospital and the department of GIT bleeding and liver disease. In addition, consent from the patients was signed and oral agreement after they understand what will be done in the study. This did not include or disclose any [ID] information concerning the patient. 
Ethical approval of all procedures performed in this study involving human participants were in accordance with the ethical standards of the institutional research committee and with the 1964 Helsinki declaration and its later amendments or comparable ethical standards (Kaunas Regional Committee for Biomedical Research Ethics No. BE 2-17).

Informed consent was obtained from all individual participants; if adult and parents in case of children; included in the study.

\section{Results}

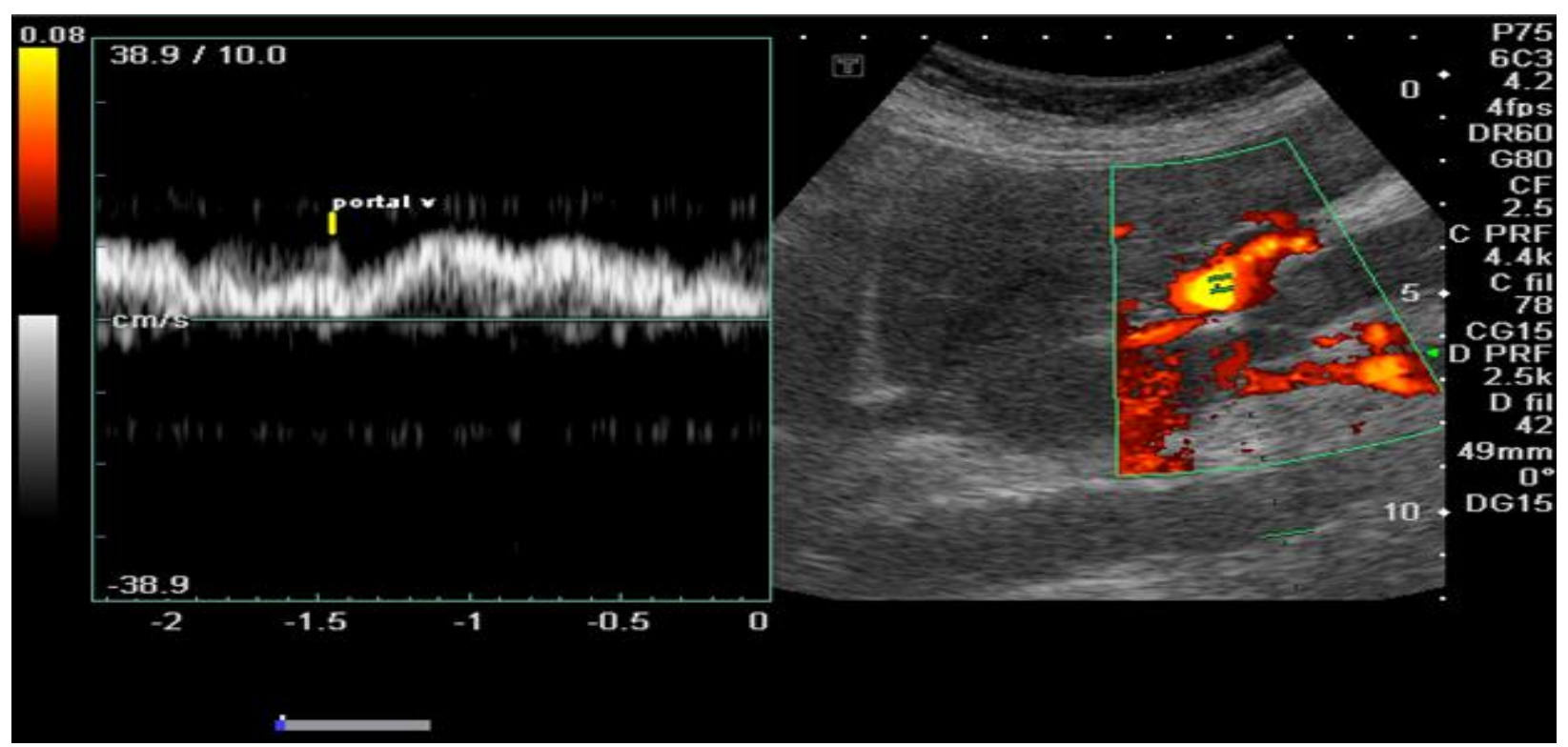

Image $\mathrm{R}_{\mathrm{I}}$ : the normal portal vein waveform.

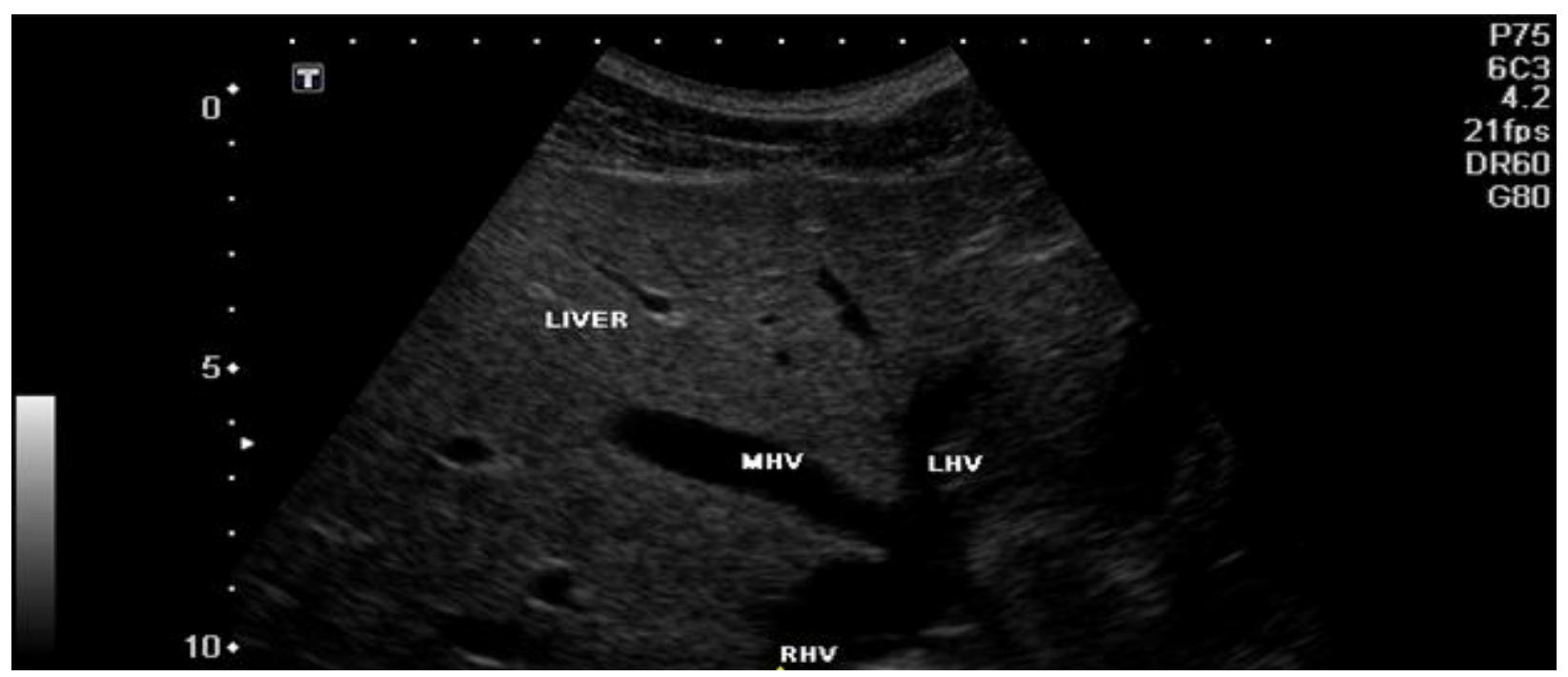

Image $\mathrm{R}_{\text {II: }}$ the three hepatic veins \& IVC in native normal liver. 


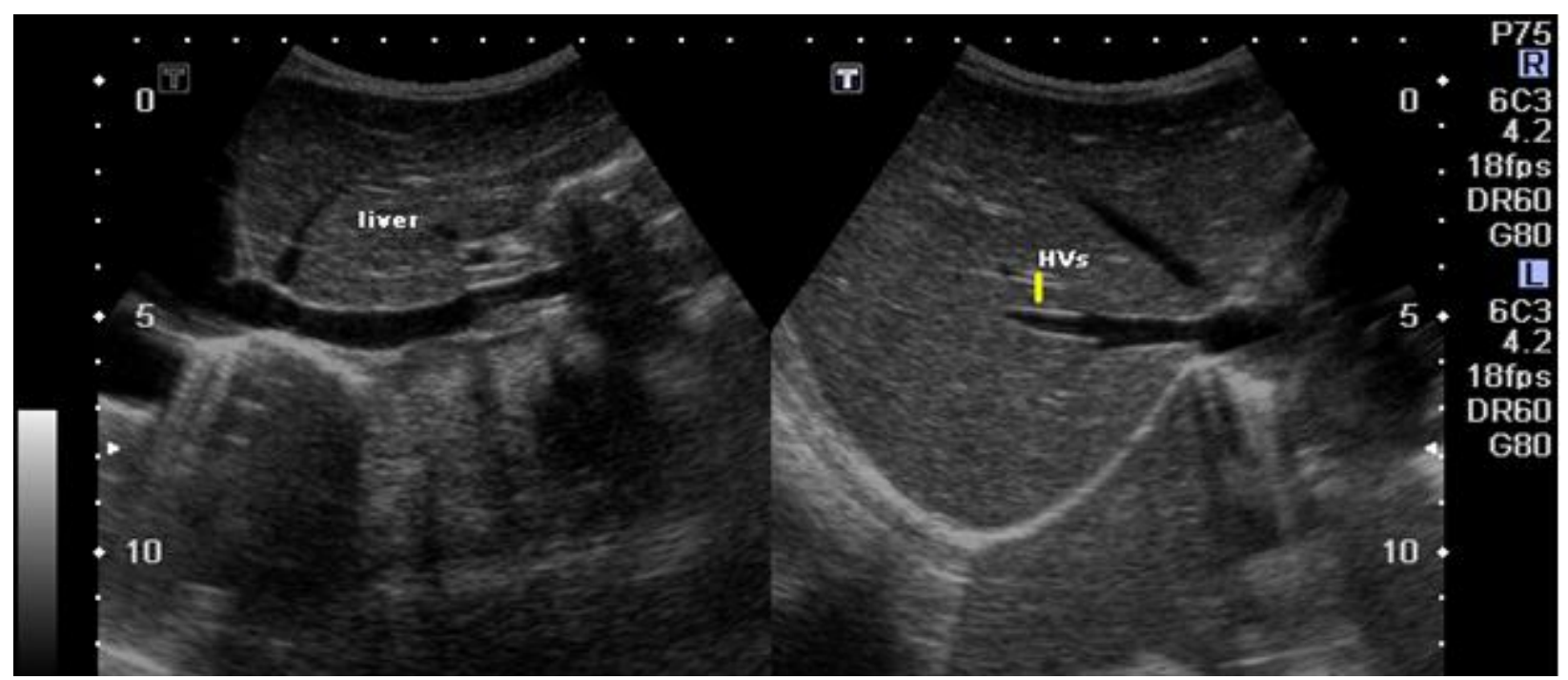

Image $\mathrm{R}_{\text {III: }}$ left lobe and the hepatic vein distribution in normal liver

Table 1: shows the sex distribution among the selected objects (patients).

\begin{tabular}{|l|l|}
\hline Gender & Frequency \\
\hline Male & 34 \\
\hline Female & 11 \\
\hline Total & 45 \\
\hline
\end{tabular}

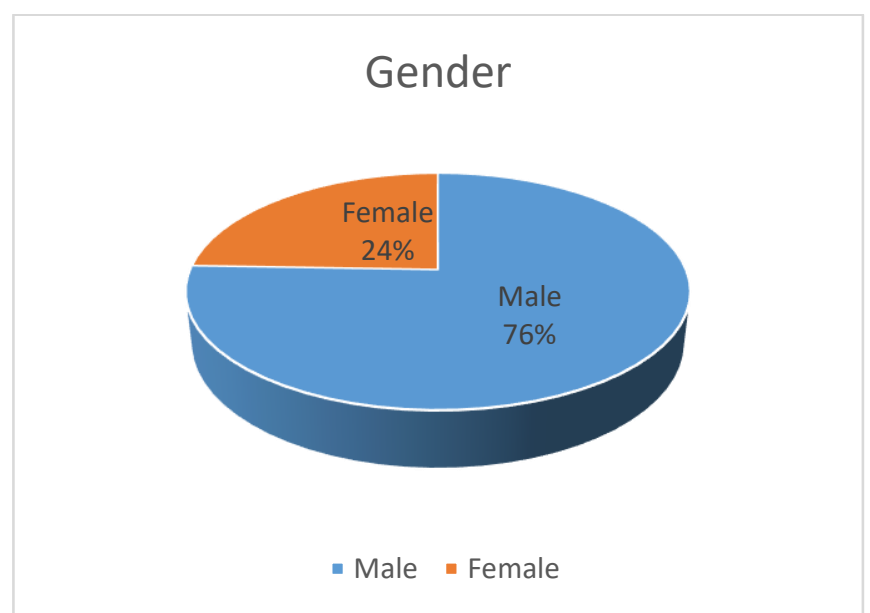

Figure 1: Pie chart represents the sex distribution percentage.

Table 2: shows the frequency distribution of the age groups in liver transplanted patients; the majority was between $34-44$ years.

\begin{tabular}{|l|l|}
\hline Age groups & Frequency \\
\hline $1-11$ & 10 \\
\hline $12-22$ & 6 \\
\hline $23-33$ & 9 \\
\hline $34-44$ & $\mathbf{1 3}$ \\
\hline $45-55$ & 3 \\
\hline $56-66$ & 4 \\
\hline
\end{tabular}


Table 3: shows the frequency distribution of the pulsatility index of the outflow veins in livertransplanted patients; the majority was between (0.65-0.70).

\begin{tabular}{|l|l|l|l|}
\hline Groups & Frequency & Waveform & Pulsatility index \\
\hline 1 & 12 & triphasic & $0.55-0.6$ \\
\hline 2 & 8 & triphasic & $0.6-0.65$ \\
\hline 3 & 15 & triphasic & $0.65-0.70$ \\
\hline 4 & 10 & triphasic & $0.70-0.75$ \\
\hline Total & 45 & triphasic & \\
\hline
\end{tabular}

\section{Discussion}

The study done during the period from $1^{\text {st }}$ April 2016 to $30^{\text {th }}$ July 2017 . This study showed that the majority of Sudanese liver transplants are males only one third are females. The Sudanese liver transplants age found to be between 1.5-65 years but the majority ranges between (34-44 years), nine of them are children below 12 years. The all waveforms of the tested Sudanese HVs and the IVC was found a triphasic character, with three waves, the so-called atrial wave above the baseline, short systolic wave, and long diastolic wave both are below the baseline. The pulsatility index was found in the range of $0.55-0.75$ and the majority in the field of 0.65-0.70, which is a little bit below the normal one.

\section{Conclusion}

The main objective of this study was to evaluate the transplanted liver among Sudanese persons using Doppler ultrasonography in order to find the cardinal differences between the normal and the transplanted liver outflow and to detect the vascular complications if any. No vascular complications were found, however, variation between the normal and transplanted liver was seen in the length of the waveforms. Longer than normal as well as the pulsatility index, it is found to be less than normal.

Previous study showed variability between normal and transplanted liver characteristics usually attributed to ethnic groups and stenosis or occlusion is not uncommon.

\section{References}

[1] Abu-Yousef MM. Normal and respiratory variations of the hepatic and portal venous duplex Doppler waveforms with simultaneous electrocardiographic correlation. J Ultrasound Med 1992;11(6):263-8.

[2] Altinkaya N, Koc Z, Ulusan S, et al. Effects of respiratory manoeuvres on hepatic vein Doppler waveform and flow velocities in a healthy population. Eur J Radiol 2011;79(1):60-3.

[3] American Journal of Roentgenology. 2007;188: W515-W521. 10.2214/AJR.06.1262.

[4] Baik SK. Haemodynamic evaluation by Doppler ultrasonography in patients with portal hypertension: a review. Liver Int 2010;30(10):1403-13.

[5] Buell JF, Funaki B, Cronin DC, Yoshida A, Perlman MK, Lorenz J, et al. Long-term venous complications after full-size and segmental pediatric liver transplantation. Ann Surg. 2002; 236:658-66.

[6] Gallix BP, Taourel P, DauzatM, et al. Flow pulsatility in the portal venous system: a study of Doppler sonography in healthy adults. AJR Am J Roentgenol 1997;169 (1):141-4. 
[7] Gielecki J, Zurada A, Sonpal N, et al. The clinical relevance of coeliac trunk variations. Folia Morphol 2005;64(3):123-9.

[8] Grenier N, Basseau F, Rey MC, et al. Interpretation of Doppler signals. Eur Radiol 2001;11(8):1295-307.

[9] Ko EY, Kim TK, Kim PN, Kim AY, Ha HK, Lee MG. Hepatic vein stenosis after living donor liver transplantation: Evaluation with Doppler US. Radiology. 2003:806-10.

[10] Kruskal JB, Newman PA, Sammons LG, et al. Optimizing Doppler and color flow US: application to hepatic sonography. Radiographics 2004;24(3):657-75.

[11] Lafortune M,Madore F, Patriquin H, et al. Segmental anatomy of the liver: a sonographic approach to the Couinaud nomenclature. Radiology 1991;181(2):443-8.

[12] McNaughton DA, Abu-Yousef MM. Doppler US of the liver made simple. Radiographics 2011;31(1):161-88.

[13] Ohta M, Hashizume M, Kawanaka H, et al. Prognostic significance of hepatic vein waveform by Doppler ultrasonography in cirrhotic patients with portal hypertension. Am J Gastroenterol 1995;90(10):1853-7.

[14] Oppo K, Leen E, Angerson WJ, et al. Doppler perfusion index: an interobserver and intraobserver reproducibility study. Radiology 1998;208(2):453-7.

[15] Sacerdoti D, Merkel C, Bolognesi M, et al. Hepatic arterial resistance in cirrhosis with and without portal vein thrombosis: relationships with portal hemodynamics. Gastroenterology 1995;108(4):1152-8.

[16] Shapiro RS, Winsberg F, Maldjian C, et al. Variability of hepatic vein Doppler tracings in normal subjects. J Ultrasound Med 1993;12(12):701-3.

[17] Sutherland T, Temple F, Lee WK, et al. Evaluation of focal hepatic lesions with ultrasound contrast agents. J Clin Ultrasound 2011;39(7):399-407.

[18] Tamsel S, Demirpolat G, Killi R, Aydin U, Kilic M, Zeytunlu M, et al. Vascular complications after liver transplantation: Evaluation with Doppler US. Abdom Imaging. 2007; 32:339-47.

[19] Wang SL, Sze DY, Busque S, Razavi MK, Kee ST, Frisoli JK, et al. Treatment of hepatic venous outflow obstruction after piggyback liver transplantation. Radiology. 2005; 236:352-9.

[20] Wood MM, Romine LE, Lee YK, et al. Spectral Doppler signature waveforms in ultrasonography: a review of normal and abnormal waveforms. Ultrasound Q 2010;26(2):83-99.

*Corresponding author.

E-mail address: ashrafmerafabi@gmail.com 